\title{
Business plan feedback for cost effective business processes
}

\author{
Ivanisevic, A. ${ }^{a,}{ }^{*}$, Katic, I. ${ }^{a}$, Buchmeister, B. ${ }^{b}$, Leber, M. ${ }^{b}$ \\ a University of Novi Sad, Faculty of technical sciences, Novi Sad, Serbia \\ ${ }^{b}$ University of Maribor, Faculty of Mechanical Engineering, Maribor, Slovenia
}

\begin{abstract}
A B S T R A C T
Business planning encompasses all the goals, strategies and actions to ensure company's business survival, prosperity, and growth. Literature review and analysis of business processes of production systems show that the business plan is considered as a rigid system, even though it is being prepared in a world of constantly changing business conditions. The possibility of correction of a business plan that is being realized in the course of a year is only a theoretical possibility, and the introduction of a feedback system as an element of correction remains only as an idea. The aim of this paper is to propose and introduce a system in the business technology that would be similar to the designing principles for automated technical systems. In the paper an original business planning model with feedback is presented. The model includes planning, monitoring and harmonization of business operations. It is appropriate for unstable conditions too, regarding the essential influences from the business environment, thus adapting the company's operations. It could be used in small-and medium-sized companies, in industries of all types. The model enables the assessment of present and future business results. Verification of the model has been successfully carried out at three levels.
\end{abstract}

\section{ARTICLE INFO}

Keywords:

Cost-effectiveness

Feedback

Business plan

Business process

External and internal influences

*Corresponding author:

andreai@uns.ac.rs

(Ivanisevic, A.)

Article history:

Received 21 March 2016

Revised 3 August 2016

Accepted 16 August 2016

\section{References}

[1] Badri, M.A., Davis, D., Davis, D. (2000). Operations strategy, environmental uncertainty and performance: a path analytic model of industries in developing countries, Omega, Vol. 28, No. 2, 155-173, doi: 10.1016/S03050483(99)00041-9.

[2] Dyner, I., Larsen, E.R. (2001). From planning to strategy in the electricity industry, Energy Policy, Vol. 29, No. 13, 1145-1154, doi: 10.1016/S0301-4215(01)00040-4.

[3] Leković, B., Ivanišević, A., Marić, B., Demko-Rihter, J. (2013). Assessment of the most significant impacts of environment on the changes in company cost structure, Economic Research, Vol. 26, No. 1, 225-242, doi: $10.1080 / 1331677 X .2013 .11517599$.

[4] Dean Jr, J.W., Sharfman, M.P. (1996). Does decision process matter? A study of strategic decision-making effectiveness, Academy of Management Journal, Vol. 39, No. 2, 368-392, doi: 10.2307/256784.

[5] Delmar, F., Shane, S. (2003). Does business planning facilitate the development of new ventures?, Strategic Management Journal, Vol. 24, No. 12, 1165-1185, doi: 10.1002/smj.349.

[6] Honig, B. (2004). Entrepreneurship education: Toward a model of contingency-based business planning, Academy of Management Learning \& Education, Vol. 3, No. 3, 258-273, doi: 10.5465/AMLE.2004.14242112.

[7] Oltra, M.J., Flor, M.L. (2010). The moderating effect of business strategy on the relationship between operations strategy and firms' results, International Journal of Operations and Production Management, Vol. 30, No. 6, 612638, doi: $10.1108 / 01443571011046049$.

[8] Miller, C.C., Cardinal, L.B. (1994). Strategic planning and firm performance: A synthesis of more than two decades of research, Academy of Management Journal, Vol. 37, No. 6, 1649-1665, doi: 10.2307/256804.

[9] Bittlingmayer, G. (2001). Regulatory uncertainty and investment: Evidence from antitrust enforcement, Cato Journal, Vol. 20, No. 3, 295-325. 
[10] Vedenik, G., Leber, M. (2015). Change management with the aid of a generic model for restructuring business processes, International Journal of Simulation Modelling, Vol. 14, No. 4, 584-595, doi: 10.2507/IJSIMM14 (4)2.302.

[11] Nguyen, D.M. (2015). A new application model of lean management in small and medium sized enterprises, International Journal of Simulation Modelling, Vol. 14, No. 2, 289-298, doi: 10.2507/IJSIMM14(2)9.304.

[12] Cerjaković, E., Topčić, A., Tufekčić, D., Veža, I. (2015). Influence of structure of manufacturing system and amount of investment on production costs, Tehnički Vjesnik - Technical Gazette, Vol. 22, No.3, 771-780, doi: $10.17559 / \mathrm{TV}-20140307103216$.

[13] Zhao, R. (2012). Simulation-based environmental cost analysis for work-in-process, International Journal of Simulation Modelling, Vol. 11, No. 4, 211-224, doi: 10.2507/IJSIMM11(4)4.218. 


\section{APEM}

Advances in Production Engineering \& Management Letnik 11 | Številka 3 | September 2016 | Strani 159-172 http://dx.doi.org/10.14743/apem2016.3.217
ISSN 1854-6250

Spletna stran: apem-journal.org Izvirni znanstveni članek

\section{Sistem spremljanja proizvodnje za razumevanje robustnosti izdelka}

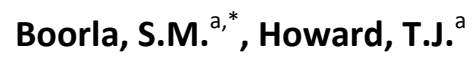

${ }^{a}$ Technical University of Denmark, Department of Mechanical Engineering, Denmark

\section{POVZETEK}

V proizvodnji zagotavljamo konstantno kakovost (lastnost) izdelka tako, da zagotovimo, da so lastnosti njegovih sestavin v okviru proizvodnih specifikacij. Lastnost izdelka se preverja po končni montaži. Vendar pa ta pristop ne nadzira robustnosti lastnosti izdelka, tj. koliko se bo razlikoval od specificiranih lastnosti. $V$ pričujoči raziskavi je predlagan model za napovedovanje lastnosti izdelka, ki upošteva zasnovo, montažo in procesne parametre neposredno iz proizvodnje. To omogoča, da v proizvodnji ohranjamo končne lastnosti izdelka namesto zgolj lastnosti njegovih sestavnih delov. Da bi prikazali kako je lahko sistem spremljanja uspešen pri vodenju korektivnih akcij za izboljšanje lastnosti izdelka smo uporabili PRECI-IN študijo primerov. Za podkrepitev teze, da lahko sistem spremljanja bistveno skrajša čas za identifikacijo, načrtovanje in izvedbo korektivnih akcij povezanih s kakovostjo izdelka, smo izvedli dve študiji primerov iz različnih industrijskih okolij. Intervjuji s strokovnjaki s področja kakovosti so pokazali, da je značilen čas, potreben za korektivne akcije, znašal v obeh primerih okoli sedem dni. Z uporabo sistema za spremljanje (PRECI-IN) pa so podobne korektivne akcije bile izvedene domala takoj.

\section{PODATKI O ČLANKU}

Ključne besede:

Robustnost izdelka

Spreminjanje lastnosti

Sistem za spremljanje robustnosti

Konsistentnost lastnosti

Robustnost element-element

*Kontaktna oseba:

srimbo@mek.dtu.dk

(Boorla, S.M.)

Zgodovina članka:

Prejet 27. maja 2016

Popravljen 5. avgusta 2016

Sprejet 17. avgusta 2016 